\title{
Dynamic thermal response of low-energy residential buildings based on in-wall measurements
}

\author{
Kyriaki Foteinaki ${ }^{1, *}$, Rongling Li $^{1}$, Alfred Heller $^{2}$, Morten Herget Christensen ${ }^{3}$ and Carsten Rode ${ }^{1}$ \\ ${ }^{1}$ Technical University of Denmark, Department of Civil Engineering, Brovej, Building 118, 2800 Kgs.Lyngby, Denmark \\ ${ }^{2}$ Niras, Østre Havnegade 12, 9000 Aalborg, Denmark \\ ${ }^{3}$ Technical University of Denmark, Department of Electrical Engineering, Ørsteds Plads, Building 348, 2800 Kgs.Lyngby, Denmark
}

\begin{abstract}
This study analysed the dynamic thermal response of a low-energy building using measurement data from an apartment block in Copenhagen, Denmark. Measurements were collected during February and July 2018 on space heating energy use, set-points, room air temperature and temperature from sensors integrated inside concrete elements, i.e. internal walls and ceiling, at different heights and depths. The heating system was controlled by the occupants. During February, there were unusually high set-points for some days and a regular heating pattern for some other days. Overheating was observed during July. A considerable effect of solar gain was observed both during winter and summer months. The room air temperature fluctuations were observed at a certain extent inside the concrete elements; higher in the nonload-bearing internal wall, followed by the load-bearing internal wall and lastly by the ceiling. The phenomenon of delayed thermal response of the concrete elements was observed. All internal concrete masses examined may be regarded as active elements and can contribute to the physically available heat storage potential of the building. The study provides deep insight into the thermal response of concrete elements in low-energy residential buildings, which should be considered when planning a flexible space heating energy use.
\end{abstract}

\section{Introduction}

In the future energy system a significant increase in the penetration of renewable energy is expected. As a consequence, the fluctuating energy production from renewable energy sources will challenge the controllability and stability of the power grid. Many studies propose energy flexibility as a solution to facilitate secure operation of the energy system while integrating a large share of renewables, as an example [1], [2]. The residential building sector, which constituted $27 \%$ of the final energy consumption in Europe in 2016 [3], offers great potential for flexibility as the large thermal mass of the building stock could be utilized for energy storage. The new generation of buildings in Denmark are well-insulated and airtight, according to the Danish Building Regulation 2018 [4] and may be heavy-weight, namely have large thermal storage capacity. There have been many studies showing the potential of the structural thermal mass of buildings to be utilized as storage medium to offer flexibility [5][12]. Most studies perform simulations aiming at moving load in time to avoid demand in peak load periods, or to promote demand in off-peak periods, imposing heating strategies that exploit the dynamic thermal response of the concrete mass. Some studies have performed analysis on the effect of the material properties pertaining to thermal mass on the flexibility potential [10], [12], and the contribution of different building components to flexibility [5], [6]. To the knowledge of the authors, no recent full scale monitoring has been performed to document in detail the behaviour of the thermal mass.

The purpose of the present work is to analyse the dynamic thermal response of a low-energy building using measurement data. The case study building is a multi-family apartment block, located in Copenhagen, Denmark. Measurements are collected during the year 2018. Data on space heating energy use, indoor air temperature, $\mathrm{CO}_{2}$ concentration and relative humidity are used to evaluate the energy performance and indoor environment of the apartments. In addition, a set of temperature sensors have been placed inside the prefabricated concrete walls and ceilings, at different depths from the surface to the middle of the concrete layer. This unique set of measurements allows for analysis of the dynamic thermal response of the thermal mass of the building, and it demonstrates which part of the thermal mass actively participates in the heat exchange with the indoor environment and can subsequently facilitate load shifting strategies.

The structure of this paper is organized as follows. Section 2 presents the case study building, the monitoring system, and by the methodology of data analysis. In Section 3 the results of the measurements are analysed and discussed. The main conclusions are summarized in Section 4.

\footnotetext{
*Corresponding author: kyfote@byg.dtu.dk
} 


\section{Methodology}

\subsection{Case study building}

The case study building is a multi-family apartment block that was completed in 2017 and is located in Nordhavn district of Copenhagen, Denmark. The building has 72 apartments and 11 town house units. 19 apartments and 1 town house unit agreed to participate in the EnergyLab Nordhavn project [13], monitoring the energy use, indoor environment and temperatures inside the concrete elements. In the present analysis, one apartment has been chosen in order to analyse in depth the thermal response of concrete elements and develop the methodology that will be applied to the other apartments in future work.

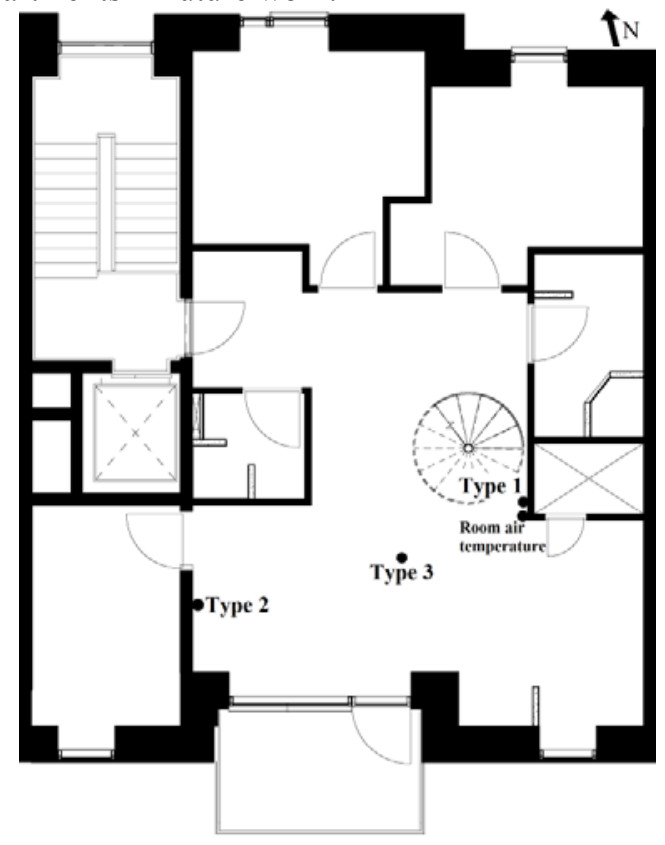

Fig. 1. Apartment floor plan and installed sensors [14].

The apartment has an area of $147 \mathrm{~m}^{2}$. It is on the top floor ( $5^{\text {th }}$ floor) of the building and has a loft. It has facades to the south and north, while on the east and west sides there are adjacent apartments. Fig. 1 shows the floor plan of the apartment (excluding the loft). Table 1 lists the properties of the main building components.

Table 1. Properties of main building components.
The building is connected to the district heating system and the heat emission system in the apartment is floor heating. There is CAV mechanical ventilation and heat recovery from exhaust air with $85 \%$ efficiency. Fresh air is supplied in the living room and bedrooms and it is exhausted from the kitchen, bathroom and toilet.

\subsection{Monitoring system}

The apartment is equipped with sensors measuring air temperature, $\mathrm{CO}_{2}$ concentration and relative humidity. There is a home management system which includes control of the heating system via control panels with integrated room air temperature sensors placed in each room. Furthermore, for research purposes, there are custom-made concrete blocks of size $(60 \times 200 \times 200$ $\mathrm{mm}$ ) with built-in sensors that measure the temperature at different depths. The concrete blocks were prepared in the laboratory of Technical University of Denmark (DTU), with three integrated temperature sensors, at the surface and at two depths into the material. The sensors used are PT 1000 (DIN EN 60751, CLASS DIN B). The sensors' heads are in direct contact with the concrete that surrounds them, while the sensor cables are covered with a flexible plastic pipe that leads out of the concrete block, to protect them when the sensor block was cast into the concrete wall and ceiling elements. Fig. 2 depicts the production process of the concrete blocks. These concrete blocks were subsequently cast into walls and ceilings during the production process. Three different types of setup have been created and are illustrated in Fig. 3.

- Type 1: Sensors were placed in the internal nonload-bearing wall made of $100 \mathrm{~mm}$ of aerated concrete, at a height above the floor of $1.1 \mathrm{~m}$ and at three depths: $0 \mathrm{~mm}, 25 \mathrm{~mm}$ and $50 \mathrm{~mm}$ from the internal surface.

- Type 2: Sensors were placed in the internal loadbearing wall made of $200 \mathrm{~mm}$ concrete, at the same height of $1.1 \mathrm{~m}$ and at three depths: $0 \mathrm{~mm}, 50 \mathrm{~mm}$ and $100 \mathrm{~mm}$ from the internal surface of the living room. Three more sensors were placed in the surface layer at heights $0.1 \mathrm{~m}, 0.6 \mathrm{~m}$ and $1.7 \mathrm{~m}$.

- Type 3: Sensors were placed in the ceiling, in the layer that consisted of $220 \mathrm{~mm}$ concrete, at three depths: $0 \mathrm{~mm}, 55 \mathrm{~mm}$ and $110 \mathrm{~mm}$ from the lower surface. On top of the concrete there is thermal insulation.

\begin{tabular}{|c|c|c|c|}
\hline Components & Thickness [mm] & U-value $\left[\mathbf{W} /\left(\mathrm{m}^{2} \mathrm{~K}\right)\right]$ & Materials \\
\hline External wall & 580 & 0.122 & $\begin{array}{c}\text { Concrete }(180 \mathrm{~mm}) \\
\text { Insulation class } 38(300 \mathrm{~mm}) \\
\text { Concrete }(70 \mathrm{~mm}) \\
\text { Air gap }(5 \mathrm{~mm}) \\
\text { Aluminium plates }(25 \mathrm{~mm}) \\
\end{array}$ \\
\hline Internal load-bearing wall & 200 & 3.70 & Concrete $(200 \mathrm{~mm})$ \\
\hline Internal non-load-bearing wall & 100 & 1.35 & Aerated concrete $(100 \mathrm{~mm})$ \\
\hline Floor/ceiling decks & 407 & 0.34 & $\begin{array}{c}\text { Oak planks }(14 \mathrm{~mm}) \\
\text { Concrete }(80 \mathrm{~mm}) \\
\text { Insulation class } 38(93 \mathrm{~mm}) \\
\text { Hollow core concrete }(220 \mathrm{~mm})\end{array}$ \\
\hline Windows & 3 pane glazing & 0.72 & $\begin{array}{c}g \text {-value }=0.5, \\
\text { frame fraction } 15 \% \\
\text { window frame } U \text {-value }=0.85\end{array}$ \\
\hline
\end{tabular}


The sensors, listed in Table 2, were placed in elements facing the large open space (which includes the living room and kitchen, further referred to as the living room), as depicted in Fig. 1.

All measurement data were received by a KNX system and were transferred to a central data management system at DTU. The time resolution of the data was $1 \mathrm{~min}$. Ambient weather data were obtained from the Climate Station at DTU [15] for the months of the analysis. The weather station is located $10 \mathrm{~km}$ from the measured apartment, so a deviation in the weather data is expected. However, this is not considered critical for the present analysis.

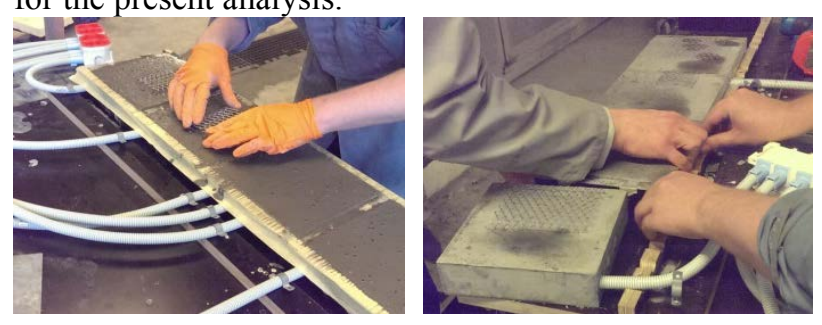

Fig. 2. Production process of concrete blocks with integrated temperature sensors.

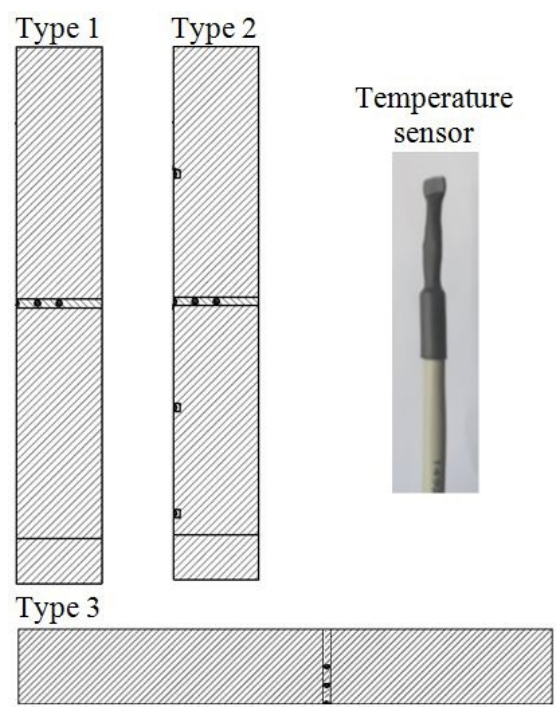

Fig. 3. Placement of temperature sensors in walls (Type 1 and Type 2) and ceiling (Type 3).

\subsection{Data analysis}

The analysis was performed for one winter month, February, and one summer month, July. The space heating energy use, $\mathrm{CO}_{2}$ concentration and relative humidity are reported here. The main goal of the analysis was to determine the dynamic thermal response of the apartment. Room air temperature is therefore discussed, in relation to solar gains and the resulting heating patterns. In-depth analysis of temperature from the different nodes inside the concrete elements at different heights and depths was performed. The nodes inside each concrete element were examined in relation to the room air temperature to which the elements were exposed. The data shown are from the living room. For each month, two days were chosen, to provide more detail in the analysis of the thermal response. The temperature fluctuations of all nodes in the concrete elements were normalized, in order to evaluate what percentage of the room air temperature fluctuation was achieved at different depths in the concrete (Eq.1), and to evaluate the delay in thermal response (Eq.2):

$$
\begin{aligned}
& \text { - } T_{\text {norm } 1}=\frac{T_{\text {node }}-T_{\text {node }(\min )}}{T_{\text {room }(\max )}-T_{\text {room }(\min )}} \\
& \text { - } \quad T_{\text {norm } 2}=\frac{T_{\text {node }}-T_{\text {node }(\min )}}{T_{\text {node }(\max )}-T_{\text {node }(\min )}}
\end{aligned}
$$

Table 2: Temperature sensors in walls and ceiling.

\begin{tabular}{|l|l|l|l|}
\hline Sensor & Element & Depth & Height \\
\hline T1-0 mm & Wall & Surface & $1.1 \mathrm{~m}$ \\
\hline T1-25 mm & Wall & $25 \mathrm{~mm}$ & $1.1 \mathrm{~m}$ \\
\hline T1-50 mm & Wall & $50 \mathrm{~mm}$ & $1.1 \mathrm{~m}$ \\
\hline T2-0 mm-1.1 m height & Wall & Surface & $1.1 \mathrm{~m}$ \\
\hline T2-50 mm & Wall & $50 \mathrm{~mm}$ & $1.1 \mathrm{~m}$ \\
\hline T2-100 mm & Wall & $100 \mathrm{~mm}$ & $1.1 \mathrm{~m}$ \\
\hline T2-0 mm -0.1 m height & Wall & Surface & $0.1 \mathrm{~m}$ \\
\hline T2-0mm -0.6 m height & Wall & Surface & $0.6 \mathrm{~m}$ \\
\hline T2-0mm -1.7 m height & Wall & Surface & $1.7 \mathrm{~m}$ \\
\hline T3-0 mm & Ceiling & Surface & $3.5 \mathrm{~m}$ \\
\hline T3-55 mm & Ceiling & $55 \mathrm{~mm}$ & $3.5 \mathrm{~m}$ \\
\hline T3-110 mm & Ceiling & $110 \mathrm{~mm}$ & $3.5 \mathrm{~m}$ \\
\hline
\end{tabular}

\section{Results and discussion}

\subsection{Measurements during winter}

The month of February 2018 had an average ambient temperature of $-1{ }^{\circ} \mathrm{C}$. Fig. 4(a) shows the ambient air temperature and the global irradiance for the whole month. The energy use for this month was $1252 \mathrm{kWh}$ $\left(8.5 \mathrm{kWh} / \mathrm{m}^{2}\right)$. Both the relative humidity and the $\mathrm{CO}_{2}$ concentration were within acceptable ranges according to EN/DS 15251 [16]; on average, the relative humidity was $30 \%$ and the $\mathrm{CO}_{2}$ concentration was $700 \mathrm{ppm}$. Fig. 4 (b) shows the heating power for the whole apartment, as well as the air temperature set-point and the air temperature in the living room. During the month there were periods with different heating patterns and thermal behaviour.

- At the beginning of the month, there was increased heating use, despite the fact that the temperature setpoint in the living room was either $21^{\circ} \mathrm{C}$ or the heating was turned off. This was due to unusually high set-points in other rooms of the apartment, which affected the air temperature in the living room. During the first three days of the month there were minimal solar gains, while from the $4^{\text {th }}-9^{\text {th }}$ there were considerable solar gains, which resulted in even higher air temperatures at midday, reaching up to $28{ }^{\circ} \mathrm{C}$. Such temperatures are considered very high, especially for the month of February. Nevertheless, the system was controlled 
entirely by the occupants based on their preferences, so extreme behaviors may be expected.

- $\quad$ From the $10^{\text {th }}-13^{\text {th }}$, the set-points in the apartment were drastically decreased, while the set-point in the living room was maintained constant at $21^{\circ} \mathrm{C}$. During these days the heating was turned off and there were very low solar gains. It took 4 days for the air temperature to decrease to $21^{\circ} \mathrm{C}$.
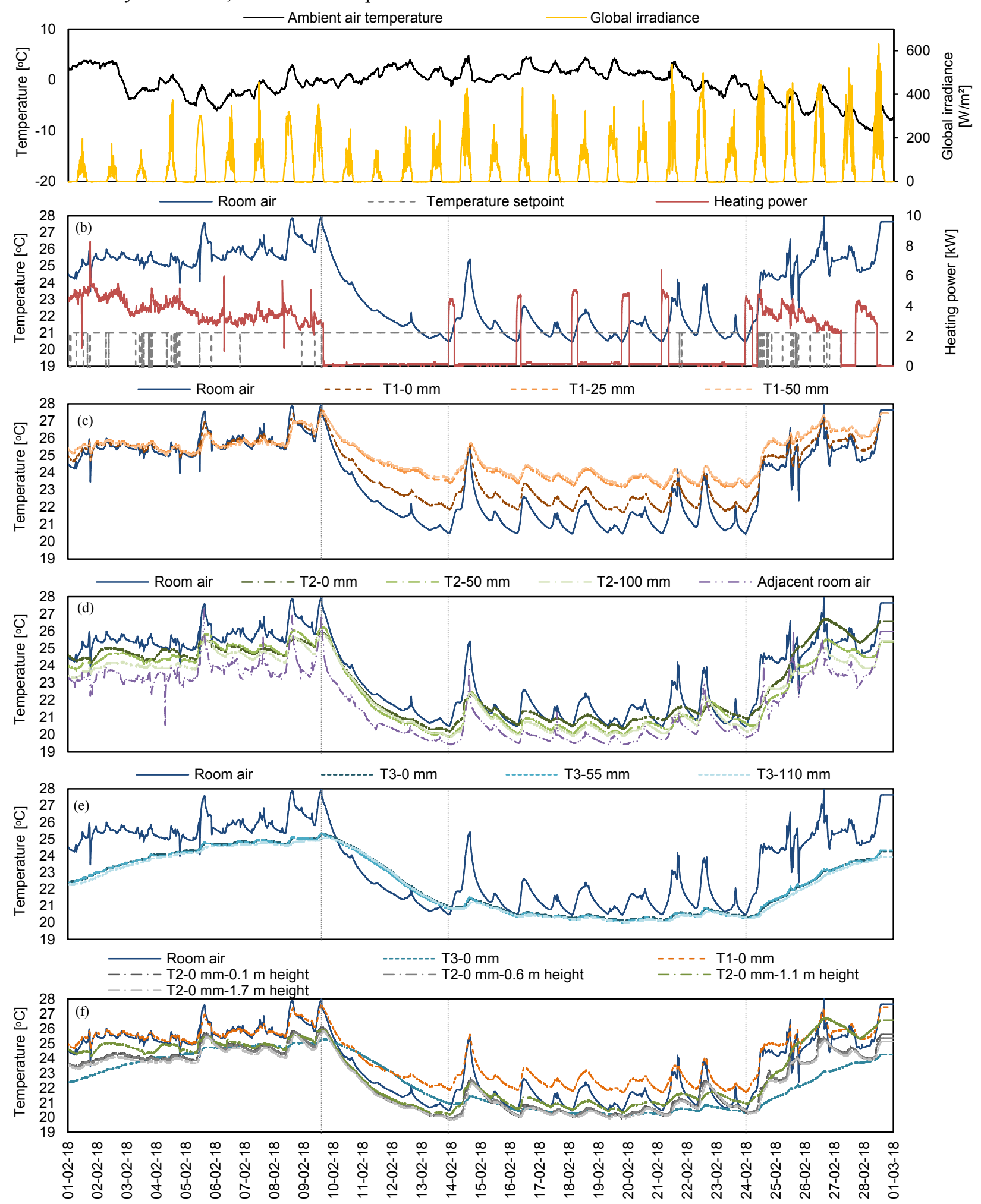

Fig. 4 Analysis of thermal response during February 2018: (a) Ambient air temperature and global irradiance. (b) Space heating power, temperature set-point and room air temperature. (c) Temperature inside the non-load-bearing internal wall at $0 \mathrm{~mm}, 25 \mathrm{~mm}$ and $50 \mathrm{~mm}$ depth and the room air temperature. (d) Temperature inside the load-bearing internal wall at $0 \mathrm{~mm}, 50 \mathrm{~mm}$ and $100 \mathrm{~mm}$ depth and the room air temperature. (e) Temperature inside the ceiling at $0 \mathrm{~mm}, 55 \mathrm{~mm}$ and $110 \mathrm{~mm}$ depth and the room air temperature. (f) Surface temperature of the concrete elements and the room air temperature. 
- With the set-point maintained at $21^{\circ} \mathrm{C}$, in the period $14^{\text {th }}-24^{\text {th }}$ the heating use was respective to the set-point in the living room. A regular heating pattern was followed; the heating system was activated during the night, ran for $4.75 \mathrm{~h}$ on average and was subsequently turned off for two days. During this period, the solar gains were average for the season, and affected the air temperature, which increased every midday.

- Towards the end of the month, the temperature setpoints of other rooms were increased again and the thermal behavior resembled what had occurred at the beginning of the month.

The above variations in the temperature set-points and respective heating patterns caused significant changes in the room air temperature, which makes it possible to examine the thermal changes inside the concrete elements.

Fig. 4(c) shows the temperatures inside the internal non-load-bearing wall (Type 1) and the room air temperature. All three sensors indicated higher temperatures than the room air temperature. The one in the middle of the wall had the highest temperature, while the other two had almost the same temperature. The other side of the wall is the utility room, so it is most likely that hot pipes traversing that room were heating it up. At the beginning of the month, when the room air temperature was also very high, this effect was not observed, but instead all the layers of the wall had an almost uniform temperature.

Fig. 4(d) shows the temperatures inside the internal load-bearing wall (Type 2) and the room air temperature of the living room and the adjacent room. The temperatures inside the internal load-bearing wall changed as expected, given that the adjacent room on the other side of the wall had a lower air temperature. They were mostly lower than the room air temperature, with the surface temperature being slightly closer to the room air temperature, followed by the temperatures at $50 \mathrm{~mm}$ and $100 \mathrm{~mm}$ depth in the concrete. Exceptions were the start of large temperature changes (increase or decrease), when due to the delayed response of the different layers, the temperatures overlapped with each other. The delay of the thermal response in different elements and depths is analysed in detail below.

Fig. 4(e) shows the temperatures inside the ceiling (Type 3) and the room air temperature. The thermal changes inside the ceiling differed from those in the walls. The three layers of the ceiling had almost the same temperature, with only negligible differences. The response to the room air temperature fluctuations was slow, and daily fluctuations could be only marginally observed, while the temperature curve responded smoothly and cumulatively to the air temperature changes. This may be because this element is exposed to room air temperature fluctuations from only one side, as there is thermal insulation above it, while the walls consist of concrete or aerated concrete and are exposed to room air temperature fluctuations from both sides. Additionally, the ceiling is not directly exposed to solar radiation, while walls may be.
Fig. 4(f) shows the surface temperature of the concrete elements and the room air temperature. The surface temperature of the internal non-load-bearing wall was the highest, for the reasons previously explained. The temperatures on the surface of the internal load-bearing wall at the different heights, $0.1 \mathrm{~m}, 0.6 \mathrm{~m}$ and $1.7 \mathrm{~m}$ were almost the same, validating the expectation that floor heating creates a uniform thermal environment with minimal vertical thermal gradients. However, the surface temperature at $1.1 \mathrm{~m}$ height was often higher than at the other heights, which indicates that there had been direct solar radiation at this height. The surface temperature of the ceiling was sometimes higher and sometimes lower than that of the rest of the surfaces, due to its slower thermal response. However, during the period with a regular heating pattern $\left(14^{\text {th }}-24^{\text {th }}\right)$, the temperature of the ceiling was very similar to those of the load-bearing internal wall. These results confirm the findings in [5], where a similar apartment was simulated and the thermal behaviour of different concrete elements was evaluated.

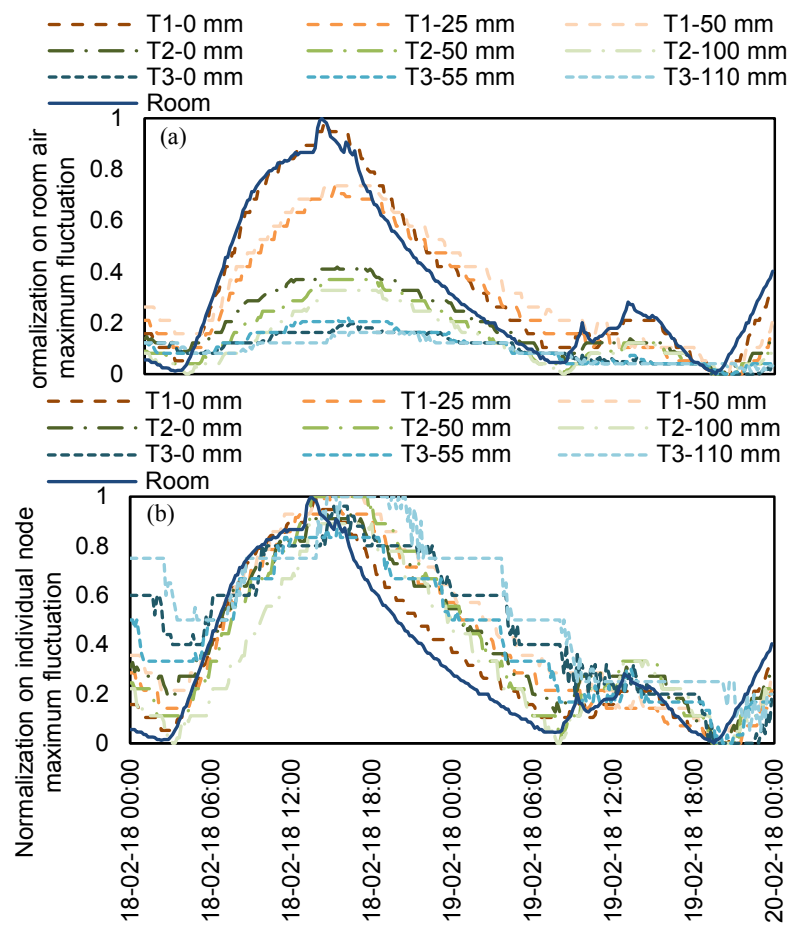

Fig. 5. Temperature fluctuations of all nodes between $18^{\text {th }}$ $19^{\text {th }}$ February. (a) Normalized against room air temperature maximum fluctuation. (b) Normalized against individual node maximum temperature fluctuation.

In order to improve the understanding of the thermal response of the different layers of the concrete elements, two days were chosen, $18^{\text {th }}-19^{\text {th }}$ February, for more detailed analysis. The temperature fluctuations of each node (i.e. each layer in each element) were normalized against the maximum fluctuation of the room air temperature for those two days. The temperature fluctuation that was achieved at the different depths of the concrete elements was thus quantified as a percentage of the room temperature fluctuation. These data are shown in Fig. 5(a). For the two days analysed, the maximum room air temperature fluctuation was $2{ }^{\circ} \mathrm{C}$. 
Comparing the temperature fluctuations achieved in the concrete elements to that of the room air temperature, the highest percentages were achieved in the non-loadbearing internal wall, followed by the load-bearing internal wall and lastly the ceiling. The surface node of the non-load-bearing internal wall experienced almost the same fluctuations as the room air temperature. The other two layers of this wall achieved a temperature increase that was as high as $74 \%$ of the room air temperature. The layers of the load-bearing internal wall achieved $43 \%, 37 \%$ and $33 \%$ for the surface, $50 \mathrm{~mm}$ and $100 \mathrm{~mm}$ node respectively. The layers of the ceiling achieved on average $19 \%$ of the room air temperature fluctuations. The room air temperature increase during the second day, which was $0.4{ }^{\circ} \mathrm{C}$, affected temperatures inside the concrete of the ceiling only marginally.
The temperature fluctuations of each node were normalized against the maximum temperature fluctuation of this node for those two days, such that the temperature fluctuation for each node varied between 0 and 1. The timing of the fluctuations can then be evaluated, quantifying the delay of the thermal response in different elements and at different depths. This is shown in Fig. 5(b). A delay of the thermal response in different elements and at different depths may be seen. During the temperature increase of the first day, the maximum delay was $2 \mathrm{~h}$ for the node that was $100 \mathrm{~mm}$ deep in the internal load-bearing wall. The delay in the non-load-bearing wall was negligible. The effect was more pronounced during the temperature decrease.
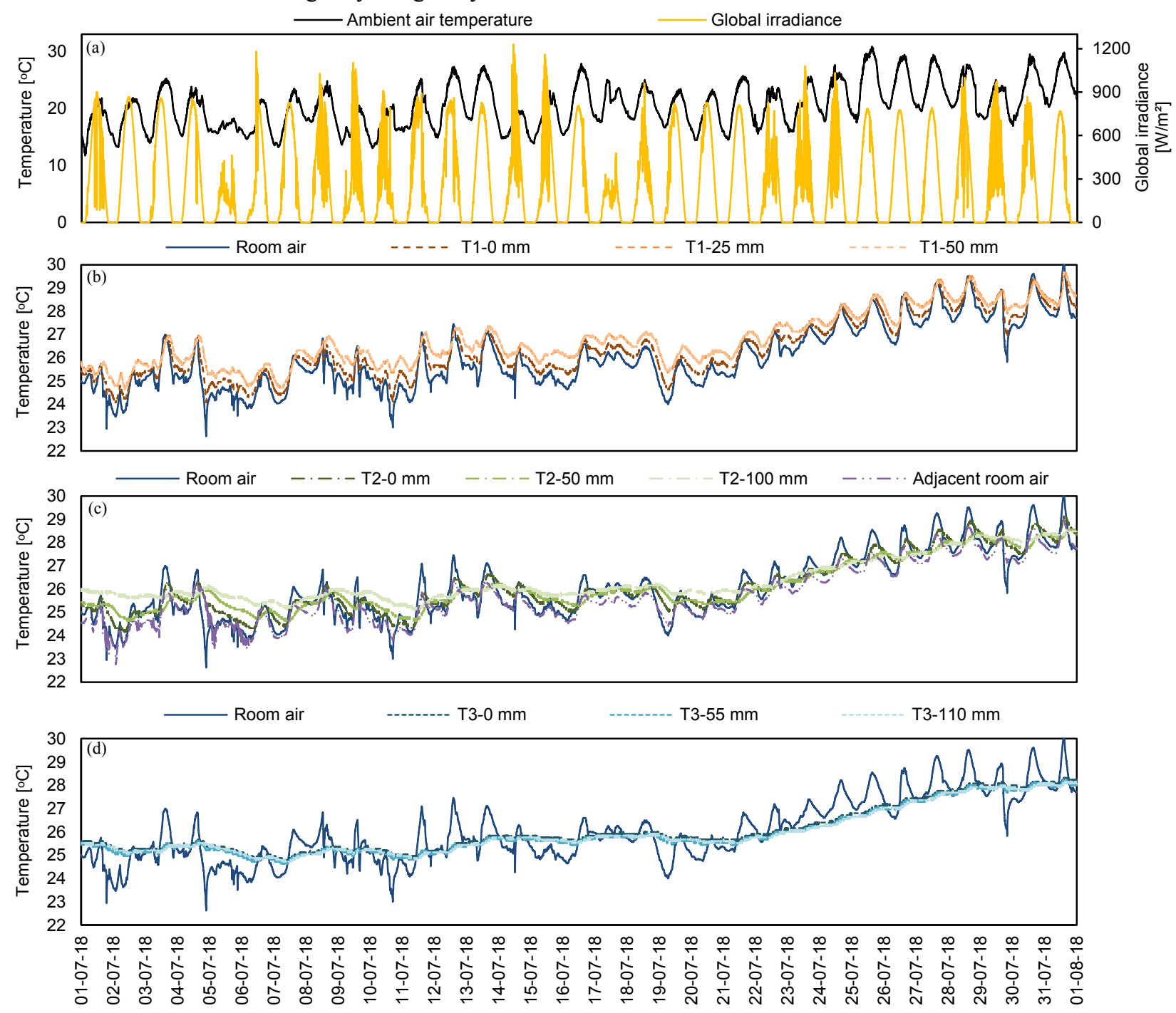

Fig. 6 Analysis of thermal response during July 2018: (a) Ambient air temperature and global irradiance. (b) Temperature inside the non-load-bearing internal wall at $0 \mathrm{~mm}, 25 \mathrm{~mm}$ and $50 \mathrm{~mm}$ depth and the room air temperature. (c) Temperature inside the loadbearing internal wall at $0 \mathrm{~mm}, 50 \mathrm{~mm}$ and $100 \mathrm{~mm}$ depth and the room air temperature. (d) Temperature inside the ceiling at $0 \mathrm{~mm}$, $55 \mathrm{~mm}$ and $110 \mathrm{~mm}$ depth and the room air temperature.

\subsection{Measurements during summer}

The month of July 2018 had an average ambient temperature $20.4{ }^{\circ} \mathrm{C}$. Fig. 6(a) shows the ambient air temperature and the global irradiance for the whole month. Both the relative humidity and the $\mathrm{CO}_{2}$ concentration were within acceptable ranges (EN/DS 15251 [16]), with the relative humidity being $50 \%$ and the $\mathrm{CO}_{2}$ concentration $470 \mathrm{ppm}$ on average. The room 
air temperature throughout the month indicates the problem of overheating observed in low-energy buildings, as the average temperature was $26{ }^{\circ} \mathrm{C}$ and reached a maximum of $30.1{ }^{\circ} \mathrm{C}$.

The changes in temperatures inside the internal nonload-bearing wall (Fig. 6(b)) were similar to what had been observed in February, namely higher than the room air temperature, due to the adjacent room being the utility room. In the load-bearing internal wall (Fig. 6(c)), the temperatures were similar and occasionally slightly higher than the room air temperature. It should be noticed that the adjacent room had almost the same temperature as the living room, whereas during February the adjacent room had on average $2{ }^{\circ} \mathrm{C}$ lower room air temperature. The temperature in the ceiling (Fig. 6(d)) was rather stable, and approximately the average of the room air temperature, since daily fluctuations are not observed in the concrete of the ceiling. Towards the end of the month, when the room air temperature was constantly increasing, so did the temperature inside the ceiling but with a smoother development.

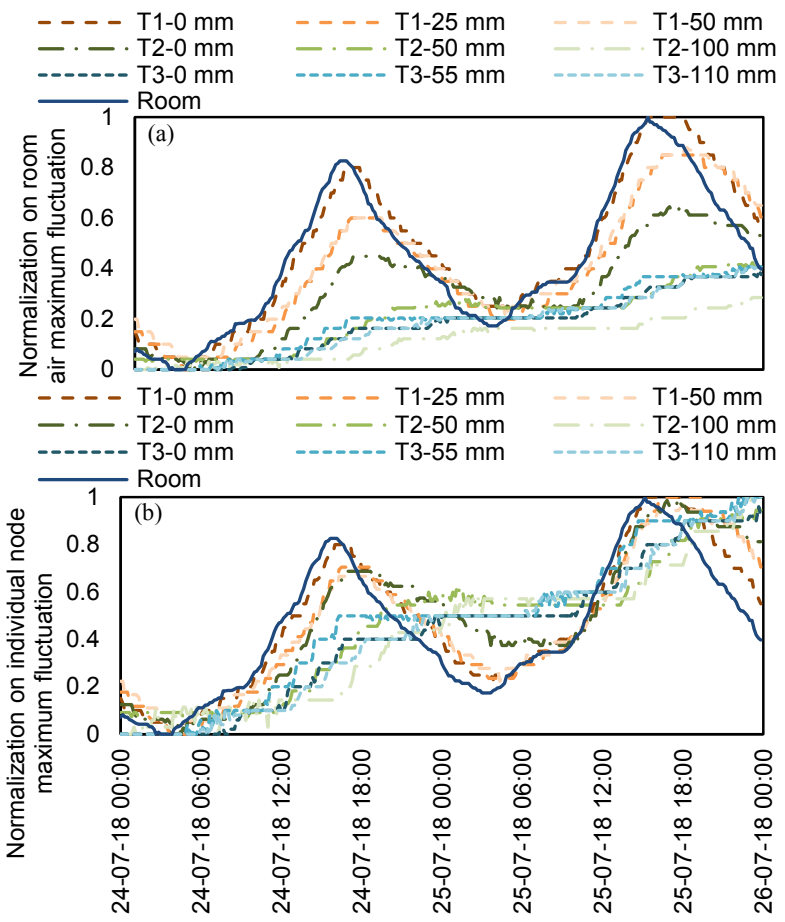

Fig. 7. Temperature fluctuations of all nodes between $24^{\text {th }}$ $25^{\text {th }}$ July. (a) Normalized against room air temperature maximum fluctuation. (b) Normalized against individual node temperature maximum fluctuation.

Two days were chosen for further analysis, $24^{\text {th }}-$ $25^{\text {th }}$ July (Fig. 7). For these two days, the maximum room air temperature fluctuation was $2{ }^{\circ} \mathrm{C}$. Regarding the temperature fluctuations achieved in the concrete elements compared to those of the room air temperature, the percentages achieved in the non-load-bearing internal wall were similar to those in February. For the layers of the load-bearing internal wall, there was larger distribution between the percentages achieved by each layer; $65 \%, 42 \%$ and $29 \%$ for the surface, $50 \mathrm{~mm}$ and $100 \mathrm{~mm}$ node respectively. The layers of the ceiling achieved on average $40 \%$ of the room air temperature fluctuations, namely double the percentage achieved during February, due to the difference between ceiling and air being smaller in summer than in winter and heat accumulated in the ceiling. Regarding the delay in response of the concrete elements compared to the room air temperature, a difference in the behaviour may be seen compared to the days in February. During the room air temperature increase due to solar gains, the delay in the response of the concrete elements was greater than that during February. Furthermore, in some nodes (i.e. $50 \mathrm{~mm}$ and $100 \mathrm{~mm}$ node in the load-bearing internal wall and all nodes in ceiling) the temperature decrease was not observed.

Nevertheless, both in February and July, the temperature fluctuations at all different depths and in all the elements indicate that the concrete elements were effectively activated by the room air temperature fluctuations. Following the assumption that were discussed by [17], in order for the thickness of a concrete element to be considered effective, more than $10 \%$ of the room air temperature fluctuations should be achieved. According to this, all layers examined may be regarded as effective, namely more than half of the concrete mass exposed to the room air temperature is effective and can actively facilitate load shifting strategies.

The conclusions of this study were based on measurements monitored while the heating system in the apartments was controlled by the occupants. The analysis clearly shows the importance of occupant behavior on energy use for space heating. Data from the same case study building have been analysed in [18], where they focused on occupant interaction with heating systems and windows. Further investigations are being performed during the heating season 2019, with the heating temperature set-points in the apartments being remotely controlled.

\section{Conclusions}

This study analysed the dynamic thermal response of a low-energy building using measurement data from a multi-family apartment block located in Copenhagen, Denmark. Measurements collected during February and July 2018 were analysed, regarding space heating energy use, heating temperature set-points, room air temperature, $\mathrm{CO}_{2}$ concentration, relative humidity, as well as a unique set of measurements from temperature sensors integrated inside concrete elements (internal walls and ceiling) at different heights and depths.

During the month of February there were periods with very different heating temperature set-points and resulting heating patterns. Unusually high set-points led to very high temperatures and heating energy use for some periods in the month of February. A considerable effect of solar gain on indoor air temperature was observed both during winter and summer months. With the contribution of solar gains and the low heat losses, in order for the apartment to maintain a temperature of 21 ${ }^{\circ} \mathrm{C}$, it was sufficient that the heating system was turned on for $4.75 \mathrm{~h}$ every other day. A problem of overheating was observed during July. The $\mathrm{CO}_{2}$ concentration and relative humidity were within acceptable ranges and the 
thermal environment was uniform with minimal vertical thermal gradients.

Comparing the temperature fluctuations achieved in the concrete elements to that of the room air temperature (defined as 100\%), the highest percentages were achieved in the non-load-bearing internal wall $(100 \mathrm{~mm}$ aerated concrete), with $87 \%$ on average, followed by the load-bearing internal wall (200 $\mathrm{mm}$ concrete) with $41 \%$, and lastly by the ceiling ( $220 \mathrm{~mm}$ hollow core concrete) with $30 \%$. Thereby, all internal concrete masses examined may be regarded as active elements and contribute to the physically available heat storage potential of the building. The phenomenon of delay in the thermal response of the concrete element was observed.

The results of this study provide deep insight into the thermal response of concrete elements in low-energy residential buildings. Important information are shown about the thermal behaviour of the structural mass of this type of buildings as a storage medium, which should be considered when planning a flexible space heating energy use to contribute to heat load shifting.

This research is part of the Danish research project "Energy- Lab Nordhavn -New Urban Energy Infrastructures" supported by the Danish Energy Technology Development and Demonstration Programme (EUDP). Project number: 640140555 .

\section{References}

[1] P. Denholm and M. Hand, Grid flexibility and storage required to achieve very high penetration of variable renewable electricity, Energy Policy, vol. 39, no. 3, pp. 1817-1830, (2011).

[2] P. D. Lund, J. Lindgren, J. Mikkola, and J. Salpakari, Review of energy system flexibility measures to enable high levels of variable renewable electricity, Renew. Sustain. Energy Rev., vol. 45, pp. 785-807, (2015).

[3] European Commission, EU Reference Scenario 2016 - Energy, transport and GHG emissions Trends to 2050, Energy, transport and GHG emissions - Trends to 2050, (2016). Available: https://ec.europa.eu/energy/sites/ener/files/docu ments/ref2016_report_final-web.pdf.

[4] Ministry of Transport Building and Housing, Executive order on building regulations 2018 (BR18), (2018). Available: http://bygningsreglementet.dk/ /media/Br/BREnglish/BR18_Executive_order_on_building_re gulations_2018.pdf.

[5] K. Foteinaki, A. Heller, and C. Rode, Modeling energy flexibility of low energy buildings utilizing thermal mass, Proceedings of IAQVEC, (2016).

[6] K. Foteinaki, R. Li, A. Heller, and C. Rode, Heating system energy flexibility of low-energy residential buildings, Energy Build., vol. 180, pp. 95-108, (2018).

[7] J. Kensby, A. Trüschel, and J.-O. Dalenbäck, Potential of residential buildings as thermal energy storage in district heating systems Results from a pilot test, Appl. Energy, vol. 137, pp. 773-781, (2015).

[8] J. Le Dréau and P. Heiselberg, Energy flexibility of residential buildings using short term heat storage in the thermal mass, Energy, vol. 111, pp. 991-1002, (2016).

[9] G. Masy, E. Georges, C. Verhelst, and V. Lemort, Smart grid energy flexible buildings through the use of heat pumps and building thermal mass as energy storage in the Belgian context, Sci. Technol. Built Environ., vol. 4731, pp. 800-811, (2015).

[10] G. Reynders, T. Nuytten, and D. Saelens, Potential of structural thermal mass for demandside management in dwellings, Build. Environ., vol. 64, pp. 187-199, (2013).

[11] G. Reynders, J. Diriken, and D. Saelens, Generic characterization method for energy flexibility: Applied to structural thermal storage in residential buildings, Appl. Energy, vol. 198, pp. 192-202, (2017).

[12] H. Wolisz, H. Harb, and P. Matthes, Dynamic simulation of thermal capacity and charging/discharging performance for sensible heat storage in building wall mass, Proceedings of IBPSA, (2013).

[13] EnergyLab Nordhavn, EnergyLab Nordhavn New Urban Energy Infrastructures, (2018). Available: http://energylabnordhavn.weebly.com/.

[14] ARKITEMA ARCHITECTS, Architectural drawings. Århus, Denmark, 2015.

[15] Technical University of Denmark (DTU) Climate Station, Department of Civil Engineering, Climate Data, (2018). Available: http:// climatestationdata.byg.dtu.dk.

[16] EN/DS 15251, Indoor environmental input parameters for design and assessment of energy performance of buildings addressing indoor air quality, thermal environment, lighting and acoustics, Dansk Stand., p. 54, (2007).

[17] J. Babiak, M. Minarova, and B. W. Olesen, What is the effective thickness of a thermally activated concrete slab?, Proceedings of ClLIMA, (2007).

[18] L. Sarran, M. H. Christensen, C. A. Hviid, A. M. Radoszynski, C. Rode, and P. Pinson, Datadriven study on individual occupant comfort using heating setpoints and window openings in new low-energy apartments - preliminary insights, CLIMA 2019 (accepted), (2019). 